\title{
CONTROLADORIA NO SETOR PÚBLICO: UMA COMPARAÇÃO ENTRE AS LEIS DE CRIAÇÃO EM QUATRO DOS MAIORES MUNICÍPIOS DE RONDÔNIA E A LITERATURA ${ }^{1}$
}

\author{
CONTROLLERSHIP IN THE PUBLIC SECTOR: A COMPARISON \\ OF THE LAWS OF CREATION IN FOUR OF THE LARGEST \\ MUNICIPALITIES IN RONDONIA AND LITERATURE
}

\author{
Nelcilene dos Reis da Silva \\ Bacharela em Ciências Contábeis pela UNIR \\ lene_vha@hotmail.com \\ Alexandre de Freitas Carneiro \\ Mestre em Administração pela UNIR \\ Professor Assistente da UNIR \\ alexandrevha95@gmail.com \\ Elder Gomes Ramos ${ }^{2}$ \\ Mestre em Administração pela FUNFEAD \\ Professor Assistente da UNIR \\ ramos.elder@gmail.com
}

\begin{abstract}
RESUMO
A Controladoria no setor público é prática recente e responsável por implantar, planejar, desenvolver e coordenar as atividades administrativas e contábeis dentro de uma organização pública. O presente artigo tem por objetivo verificar se as funções desempenhadas pelas Controladorias municipais do estado de Rondônia estão de acordo com as funções definidas na literatura. A metodologia de pesquisa seguiu uma revisão bibliográfica e se caracterizou como uma pesquisa qualitativa, descritiva, exploratória e documental. Foi realizado um estudo comparativo das legislações de criação das referidas Controladorias municipais e, após, elaborou-se um ranking entre os municípios para identificar o que mais se adequa à literatura. Inicialmente, a amostra foi planejada com os dez maiores municípios, porém pelas limitações encontradas, a mesma compreendeu quatro dos dez maiores. Os resultados da pesquisa mostraram que algumas funções estão de acordo com as definidas na literatura, outras não. As funções ou atividades descritas na literatura não encontradas na Controladoria dos municípios foram: elaborar e manter atualizado o plano de contas do município; gerenciar a contabilidade do município; planejar, coordenar e executar funções de corregedoria; planejar, coordenar e executar funções de ouvidoria; e propor medidas para racionalizar o uso dos recursos públicos, bem como a moderna função de custos. Porto Velho é o município que mais se adequa à literatura, seguido por Ji-Paraná, Ariquemes e Vilhena. Constatou-se ainda
\end{abstract}

\footnotetext{
${ }^{1}$ Recebido em 14/09/2014. Revisado por pares em 21/10/2014. 2ª versão recebida em 04/11/2014. Recomendado a publicação em 01/02/2015 por Orleans Silva Martins (Editor Geral). Publicado em 29/08/2015. Organização responsável: UFPB.

2 Endereço: Av. Rotary Club, Departamento de Ciências Contábeis, UNIR, Jardim Social, CEP 76.980-000, Vilhena/RO. DOI: http://dx.doi.org/10.18405/recfin20150205
} 
que um dos grandes municípios não criou seu órgão de Controladoria até o momento. Concluiu-se que as Controladorias municipais rondonienses têm suas funções de acordo com as descritas na literatura, de modo parcial.

Palavras-chave: Controladoria Municipal. Funções. Setor Público.

\begin{abstract}
The controllership in the public sector is recent practice and responsible for deploying, plan, develop, and coordinate activities administrative and accounting within a public organization. The purpose of this paper is to verify that the functions performed by municipal controllership of the state of Rondônia are in accordance with the functions defined in the literature. The research methodology followed a review of the literature and is characterized as a qualitative, descriptive, exploratory and documentary. Comparative study was performed of the laws of creation of such controlling and implementing municipal and, after, it produced a ranking among the municipalities, to identify the most suited to literature. Initially, the sample was planned with the ten largest cities, but because of the limitations found, the same comprised four of the top ten. The result of the survey showed that some functions are in accordance with those defined in the literature, other not. The functions or activities described in the literature, we have not found in comptroller of municipalities were: Develop and maintain updated the chart of accounts of the municipality; Manage the accounts of the municipality; Plan, coordinate and execute functions of internal affairs department; Plan, coordinate and execute functions of ombudsman; and propose measures to rationalise the use of public resources; as well as the modern function of costs. Porto Velho is the municipality that best fits the literature, followed by Ji-Paraná, Ariquemes and Vilhena. It has been noticed that, one of the major municipalities not created your component Controlling up to the moment. It was concluded that the municipal's controllership Rondônia has its functions in accordance with those described in the literature in part.
\end{abstract}

Keywords: Municipal Controllership. Functions. Public Sector.

\title{
1 INTRODUÇÃO
}

Este trabalho se enquadra na área do controle interno do setor público que é de competência das Controladorias governamentais, e o âmbito da pesquisa é nos municípios. Neles, a criação das Controladorias são recentes, aliás, o próprio órgão de controle interno federal, a Controladoria Geral da União (CGU), foi criada a pouco mais de 10 anos.

A CGU, criada pela Lei no 10.683 , em 28 de maio de 2003, é mais conhecida como agência anticorrupção do país. É o órgão encarregado de assistir direta e imediatamente ao presidente da república no desempenho de suas atribuições, fiscalizar o patrimônio público, promover a fiscalização de recursos utilizados, bem como a implantação de sistemas que tornem mais simples esse trabalho, além da otimização dos recursos disponíveis. De acordo com Castro (2013), a CGU passou a incluir entre suas responsabilidades a promoção da transparência e a prevenção e o combate à corrupção e à impunidade.

Como visto, a Controladoria no setor público é algo relativamente novo, responsável por implantar desenvolver, aplicar e coordenar todas as ferramentas da contabilidade dentro de uma organização. É de responsabilidade dos gestores públicos, o gerenciamento transparente das contas públicas, pois devem prestar contas perante a sociedade no que se refere à aplicabilidade dos recursos, e o que está sendo feito para melhorar os serviços oferecidos a comunidade, ou seja, buscase o equilíbrio entre as contas públicas e a responsabilidade fiscal, já que as exigências estão cada vez mais voltadas à transparência dos atos e fatos dos gestores públicos. Na Controladoria da administração pública é de extrema importância a busca da eficiência e eficácia na gestão de recursos públicos. 
A contabilidade para as instituições públicas tem evoluído enormemente nos últimos tempos e seu objetivo é a melhoria nas informações entre governantes e governados, evidenciando para a sociedade informação acessível quanto à utilização dos recursos públicos. A Controladoria deve cuidar de um fluxo de informações gerenciais interno e externo, nesse deve-se permitir que qualquer pessoa entenda as ações do governo, segundo Silva (2004).

Desse modo, a Controladoria pode contribuir para que os gestores públicos busquem cumprir os programas, as metas e as ações de governo num ambiente de controle dentro de um cenário transparente, eficiente e legal, pois um dos problemas no setor público é a falta de continuidade administrativa, aliado à corrupção, que devem ser sempre combatidos pelo administrador público para que lhes permitam acompanhar de perto o desenvolvimento dos serviços públicos e assegurarem a correta aplicação dos recursos e a preservação do patrimônio público.

O presente estudo se baseou na ideia de Suzart, Marcelino e Rocha (2011) que aplicaram um estudo em 14 estados brasileiros, comparando a teoria versus a prática. Desse modo, idealizou-se uma pesquisa para verificar a aplicabilidade nos municípios de Rondônia. Justificam-se novos estudos por serem recentes as Controladorias no setor público e pelo fato de a disciplina Controladoria apresentar oportunidades de aperfeiçoamento, principalmente no que se refere a publicações em periódicos, conforme Lunkes et al. (2012). Também, de acordo com Durigon e Diehl (2013), não há muitas publicações sobre o assunto, e ainda não há uma elite de pesquisadores sobre a temática, segundo Peleias et al. (2010), o que justifica novas pesquisas. Nesse contexto, surge o questionamento sobre se as funções desempenhadas pelas Controladorias descritas nas suas leis de criação, nos municípios, estão de acordo com as funções definidas na literatura.

O objetivo deste estudo é verificar se as funções desempenhadas pelas Controladorias municipais de Rondônia estão de acordo com as funções definidas na literatura. Este trabalho está estruturado, além da introdução, em outras quatro seções. Na seção 2, o referencial teórico sobre a Controladoria, suas funções e estrutura; na seção 3, os procedimentos metodológicos; os resultados e a discussão constam da seção 4; e as considerações finais são apresentadas na seção 5, incluindo as limitações e sugestões de pesquisas.

\section{FUNDAMENTAÇÃO TEÓRICA}

\subsection{Controladoria}

Slomski (2007) define a Controladoria como a busca pelo atingimento do ótimo e, para ele, seja no ramo público ou privado, o que se procura é exatamente isso, ter os melhores resultados possíveis utilizando os recursos que se têm disponíveis no momento. Pode-se então entender que a Controladoria é responsável pela garantia de um melhor funcionamento possível de todos os setores envolvidos no processo administrativo. É uma especialização responsável pela implantação e desenvolvimento contábil dentro da empresa e promover uma integração por meio das informações que auxiliam os gestores na tomada de decisão.

Para Kalife (2004), a Controladoria tem desenvolvido projetos de controle preventivo com o objetivo de tornar a administração transparente, reduzir os gastos públicos e promover a eficiência e a eficácia das atividades da prefeitura. Almeida, Parisi e Pereira (1999) ensinam que se deve observar a Controladoria sob dois aspectos: em primeiro lugar como o ramo do conhecimento, responsável por estabelecer uma base conceitual; em segundo, como órgão administrativo, responsável por disseminar o conhecimento, a modelagem e a implantação de sistemas de informação.

Mossimann e Fisch (1999) argumentam que a Controladoria tem a missão de se superar cada vez mais e, ainda, que a Controladoria consiste em um corpo de doutrinas e conhecimentos relativos à gestão econômica, podendo ser visualizada sob dois enfoques: a) como um órgão administrativo 
com uma missão, funções e princípios norteadores definidos no modelo de gestão e sistema empresa; e b) como uma área do conhecimento humano com fundamentos, conceitos, princípios e métodos oriundos de outras ciências.

No âmbito do setor público, a missão da Controladoria é, segundo Catelli (2012), coordenar a gestão econômica da organização pública, e é responsável pela elaboração dos planos estratégicos e operacionais além de execução e controle. Beuren, Schlindwein e Pasqual (2007) tiveram como objetivo traçar um perfil da pesquisa em Controladoria nos trabalhos publicados em anais do EnANPAD e do Congresso USP de Controladoria e Contabilidade, no período de 2001 a 2006. Esses autores concluíram o volume dos trabalhos ainda é pequeno comparativamente a outros temas nos mesmos eventos. Disso demanda mais estudos científicos sobre o tema.

Para Oliveira, Perez Junior e Silva (2014) a Controladoria é estruturada em dois grandes segmentos: contábil e fiscal; e planejamento e controle, conforme a Figura 1.

Figura 1 - Estrutura da Controladoria.

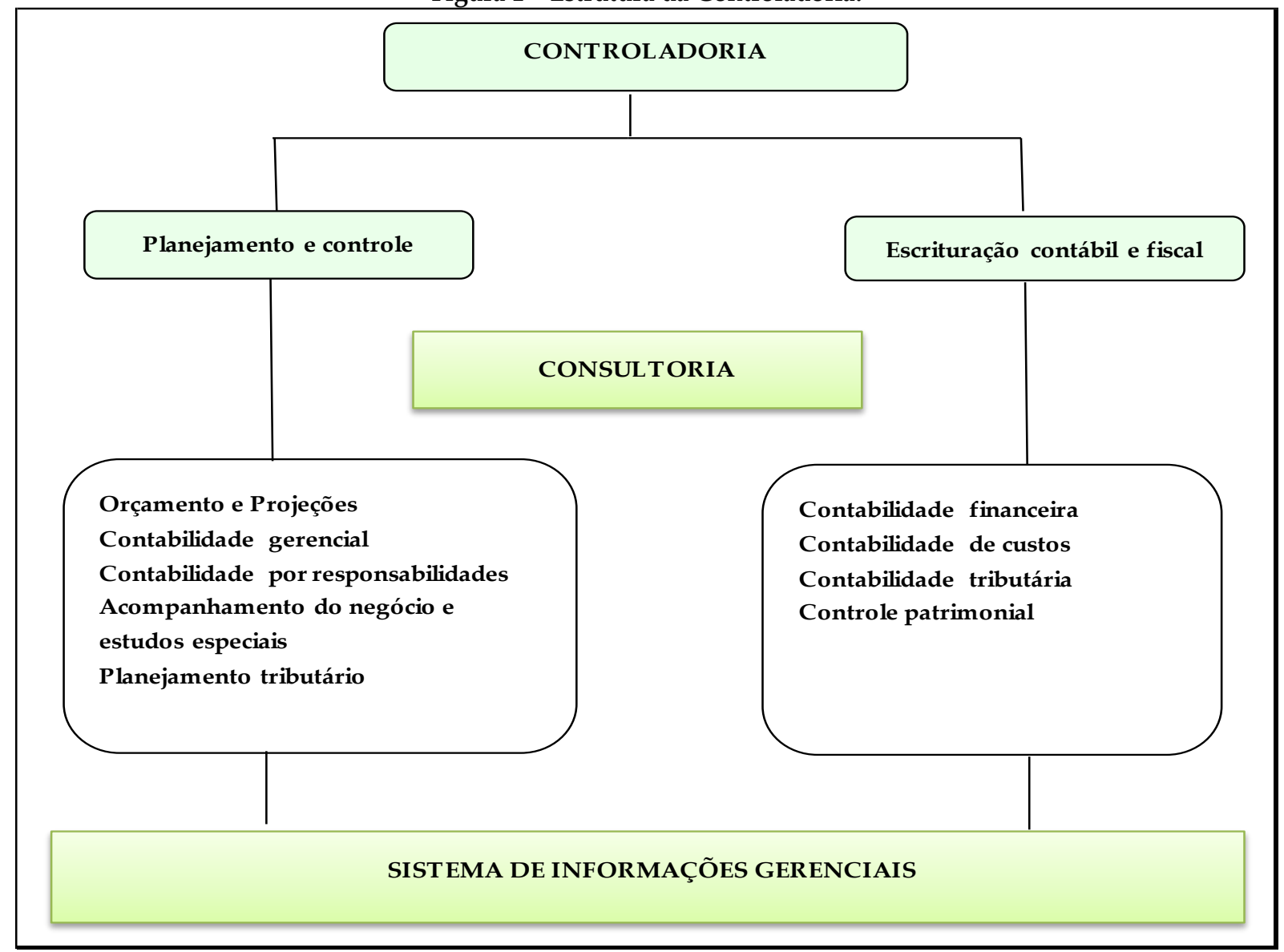

Fonte: Adaptado de Oliveira, Perez Junior e Silva (2014).

Por meio dos sistemas de informações gerenciais, a Controladoria deve promover também a consultoria à organização.

\subsection{O Controller}

Para Moura e Beuren (2003), o controller deve ter capacidade técnica para realizar as tarefas que lhe são designadas, bem como gerenciar o pessoal subordinado, e sua função dentro da empresa se amplia num leque de conhecimentos que afeta o ambiente interno e externo da empresa e exige dele estar a par de todos os aspectos que modificam ou poderão modificar a situação da empresa. 
O moderno controller, segundo Oliveira, Perez Junior e Silva (2014), deve ter uma visão proatriva e sempre dirigida para o futuro, deve ser multifuncional, e os conhecimentos exigidos para desempenhar suas funções são: contabilidade e finanças; sistemas de informações gerenciais; tecnologia de informação; aspectos legais de negócios e visão empresarial; métodos quantitativos; processos informatizados da produção de bens e serviços. É responsabilidade também do controller o estabelecimento e a manutenção de um planejamento estratégico integrado, ele deve ser encarregado da criação, pois a responsabilidade da definição do curso de ação a ser predeterminado é dos executivos, segundo Schmidt, Santos e Martins (2014).

\subsection{Funções da Controladoria}

Segundo Mossimann e Fisch (1999), a Controladoria pode ser conceituada como conjunto de princípios, procedimentos e métodos oriundos das ciências de Administração, Economia, Psicologia, Estatística e, principalmente, da Contabilidade, que se ocupam da gestão econômica das empresas, com a finalidade de orientá-las para a eficácia. Entre os requisitos necessários para o desempenho da função Controladoria, destacadas por esses autores, são: a) um bom conhecimento do ramo de atividade ao qual a empresa faz parte, assim como dos problemas e das vantagens que afetam o setor; b) um conhecimento da história da empresa e uma identificação com seus objetivos, suas metas e suas políticas, assim como com seus problemas básicos e suas possibilidades estratégicas; c) habilidade para analisar dados contábeis e estatísticos que são a base direcionadora de sua ação e conhecimento de informática suficiente para propor modelos de aglutinação e simulação das diversas combinações de dados; d) habilidade de bem expressar-se oralmente, e por escrito, e profundo conhecimento dos princípios contábeis e das implicações fiscais que afetam o resultado empresarial.

Mosimann e Fisch (1999) ainda destacam que, como um órgão administrativo, a Controladoria se materializa numa área de responsabilidade bem definida, responsável pela execução de atividades como: a) desenvolvimento de condições para a realização da gestão econômica; b) subsídio ao processo de gestão com informações em todas as suas fases, gestão dos sistemas de informações econômicas de apoio às decisões; e c) apoio à consolidação, avaliação e harmonização dos planos de ação das áreas. Continuam, esses autores, que a Controladoria como órgão administrativo tem a função de trazer informações para uma melhor avaliação e controle do desempenho das diversas áreas da empresa, assim como a função de dar apoio aos gestores no processo de tomada de decisão. A Controladoria ainda deve vetar planos e transações que não contribuam positivamente para o resultado, conforme Catelli (2012).

Segundo Almeida, Parise e Pereira (1999), os principais objetivos da Controladoria, tendo em vista a missão da organização são: a) a promoção da eficácia organizacional; b) a viabilização da gestão econômica; e c) a promoção da integração das áreas sob sua responsabilidade. Quanto à classificação da Controladoria como uma nova área do conhecimento humano com fundamentos, conceitos, princípios e métodos oriundos de outras ciências, alguns posicionamentos podem ser observados na literatura concernente. Almeida, Parise e Pereira (1999) destacam ainda que a Controladoria pode atuar como um ramo do conhecimento, responsável pelo estabelecimento das bases conceituais e teóricas, necessárias para a elaboração e continuidade do sistema de informações, dando suporte à contabilidade e à gestão da empresa.

Para Mosimann e Fisch (1999), foi a Controladoria como ramo do conhecimento que possibilitou a definição do modelo de gestão econômica e o desenvolvimento e construção dos sistemas de informações. Esses autores ainda afirmam que a Controladoria é responsável pelo estabelecimento de toda a base conceitual, estando apoiada na Teoria da Contabilidade e numa visão multidisciplinar. De acordo com eles, a Controladoria é responsável pelas bases teóricas e conceituais necessárias 
para a modelagem, construção e manutenção de Sistemas de Informações e Modelos de Gestão Econômica, que supra adequadamente às necessidades informativas dos gestores e os induzam durante o processo de gestão, quando requeridos, a tomarem decisões ótimas.

No setor público, Silva (2013) destaca os objetivos estratégicos da Controladoria do Estado de Pernambuco como: a) promoção do controle social; b) apoiar e orientar os gestores de recursos públicos; c) fornecimento de informações estratégicas; e d) acompanhamento da racionalização do gasto. Ainda, segundo Silva (2013, p.12), como coordenação dos controles internos, a Controladoria da administração pública tem como função: a) normatização em relação aos fluxos dos processos; b) criação de rotinas administrativas; c) orientações e treinamentos internos; d) assessoria e consultoria; e) apoio institucional ao controle externo; e f) melhoria contínua como garantia de cumprimento dos padrões de controle previamente estabelecidos em leis e regulamentos. No setor público, a Controladoria tem como pilares básicos tanto a transparência como a accountability, no entender de Cavalcante e De Luca (2013).

Na administração pública, segundo Oliveira (2010) e Catelli (2012) a Controladoria possui o papel de contribuir para a otimização do resultado econômico e do valor gerado pela entidade. A mensuração econômica, conforme Catelli e Santos (2004), se insere no próprio processo de gestão pública, desde a simulação e planejamento das políticas, até as etapas de execução e controle que asseguram, mediante avaliações contínuas pelos usuários, a eficácia da gestão pública no atendimento aos seus interesses e demandas.

No entender de Silva (2002), quando as funções de administração financeira, contabilidade e auditoria estão subordinadas a um mesmo órgão (principalmente a cargo da área fazendária), constata-se um retrocesso e um afrouxamento do sistema de controle. Desse modo, esse autor entende que, a contabilidade deve estar segregada da função fazendária e financeira (secretarias de fazenda), pois isso permite que os órgãos de controle externo tenham uma percepção correta da gestão sob o aspecto gerencial. Silva (2011) afirma que a contabilidade pública objetiva fornecer informações sobre, entre outras, o controle de custos e eficiência do setor público. Por possuir função de controle, a contabilidade deve, então, estar inserida na estrutura da Controladoria Geral do Município.

A Lei $\mathrm{n}^{\mathrm{o}}$ 4.320/64 trata do controle interno, nos Artigos 75 a 80, especificamente, com atribuições de cunho orçamentário. Em 1988, com a promulgação da atual Constituição Federal, no Artigo 31 diz que "a fiscalização dos municípios será exercida pelo respectivo Poder Legislativo Municipal, mediante controle externo executado com apoio do Tribunal de Contas do Estado e pelo sistema de controle interno do próprio município". Mas é no Artigo 74 que estão definidas as funções do controle interno, e são,

I - avaliar o cumprimento das metas previstas no plano plurianual, a execução dos programas de governo e dos orçamentos da União; II - comprovar a legalidade e avaliar os resultados quanto à eficácia e eficiência, da gestão orçamentária, financeira e patrimonial nos órgãos e entidades da administração federal, bem como de aplicação de recursos públicos por entidades de direito privado; III - exercer o controle das operações de crédito, avais e garantias, bem como dos direitos e haveres da União; IV - apoiar o controle externo no exercício da sua missão institucional.

$\S 1^{\circ}$ - Os responsáveis pelo controle interno, ao tomarem conhecimento de qualquer irregularidade ou ilegalidade, dela darão ciência ao Tribunal de Contas da União, sob pena de responsabilidade solidária.

Em 2000, foi publicada a Lei Complementar $n^{\circ}$ 101, denominada Lei de Responsabilidade Fiscal que, no artigo 59 determina: “O Poder Legislativo, diretamente ou com o auxílio dos Tribunais de Contas, e o sistema de controle interno de cada Poder e do Ministério Público, fiscalizarão o cumprimento das normas desta Lei Complementar". E mais recentemente, a partir de 2008, com a edição das Normas Brasileiras de Contabilidade Aplicadas ao Setor Público (sigla NBCASP alterada para 
NBC TSP), o controle interno é normatizado pela Resolução CFC no‥ 1.135/08 (CFC, 2008), da qual se destaca que,

\begin{abstract}
O controle interno sob o enfoque contábil compreende o conjunto de recursos, métodos, procedimentos e processos adotados pela entidade do setor público, com a finalidade de: (a) salvaguardar os ativos e assegurar a veracidade dos componentes patrimoniais; (b) dar conformidade ao registro contábil em relação ao ato correspondente; (c) propiciar a obtenção de informação oportuna e adequada; (d) estimular adesão às normas e às diretrizes fixadas; (e) contribuir para a promoção da eficiência operacional da entidade; (f) auxiliar na prevenção de práticas ineficientes e antieconômicas, erros, fraudes, malversação, abusos, desvios e outras inadequações.

Controle interno deve ser exercido em todos os níveis da entidade do setor público, compreendendo: (a) a preservação do patrimônio público; (b) o controle da execução das ações que integram os programas; (c) a observância às leis, aos regulamentos e às diretrizes estabelecidas.
\end{abstract}

Souza, Ortiz e Almeida (2013) estudaram a percepção dos gestores municipais da Região Sudoeste do Estado de Mato Grosso sobre utilidade de relatórios da Controladoria em geral e a adoção de um sistema de custos em particular com uma amostra composta por 22 municípios da região. Os principais achados da pesquisa, segundo esses autores, evidenciam dois aspectos: o reconhecimento da utilidade de um sistema de informação gerencial de Controladoria ao processo decisório da gestão pública e a precariedade estrutural da área de custos. Percebe-se, com base em várias pesquisas empíricas, não só a necessidade de mais estudos como o aprimoramento prático como órgão de controle interno.

\title{
2.3.1 Funções e Atividades da Controladoria na Literatura
}

A função da Controladoria dentro de uma organização, de acordo com Kanitz (1976) apud Moura e Beuren (2003, p. 56), consiste em dirigir e implantar os sistemas de,

\footnotetext{
a) Informação - compreende os sistemas contábeis e financeiros da empresa;

b) Motivação - refere-se aos efeitos dos sistemas de controle sobre o comportamento das pessoas diretamente atingidas;

c) Coordenação - assessoria e proposta de soluções que o Controlador presta à direção da empresa;

d) Avaliação - interpretação e avaliação dos resultados;

e) Planejamento - determina se os planos são consistentes e viáveis e se pode servir de base para avaliação posterior; e,

f) Acompanhamento - consiste em acompanhar de perto a evolução dos planos traçados.
}

Nesse sentido, percebe-se que o controller, o gestor da Controladoria, tem papel fundamental na formulação e no controle do planejamento estratégico da empresa, uma vez que ele fornece aos gestores os dados necessários da companhia e seu desempenho no setor possibilitando a análise das forças e fraquezas e auxiliando na formulação das estratégias de desenvolvimento.

Perez Junior (1997) salienta que a missão da Controladoria é aperfeiçoar os resultados econômicos da empresa por meio da definição de um sistema de informações baseado no modelo de gestão. Sendo assim, continua ele que, o papel da Controladoria é assessorar os gestores da empresa, mensurando as alternativas econômicas, além de integrar informações e reportá-las para facilitar a tomada de decisões.

Diversas são as funções atribuídas à Controladoria na literatura. O Quadro 1 apresenta uma síntese das funções da Controladoria destacadas por Almeida, Parísi e Pereira (2001), Piai (2000), e Borinelli (2006). 


\begin{tabular}{|c|c|c|}
\hline $\begin{array}{c}\text { Almeida, Parísi e Pereira } \\
\text { (1999) }\end{array}$ & $\begin{array}{l}\text { Piai } \\
(2000)\end{array}$ & $\begin{array}{c}\text { Borinelli } \\
(2006)\end{array}$ \\
\hline $\begin{array}{l}\text { a) Subsidiar o processo de gestão, } \\
\text { apoio e estruturação das fazes do } \\
\text { processo de gestão, mediante o uso } \\
\text { de sistema de informação que au- } \\
\text { xiliem na tomada de decisão; }\end{array}$ & $\begin{array}{l}\text { a) função informacional: situação } \\
\text { econômico-financeira desempenho } \\
\text { de setores, gestores e da organiza- } \\
\text { ção, que suportam a tomada de deci- } \\
\text { são; }\end{array}$ & $\begin{array}{l}\text { a) função contábil: gestão das ativi- } \\
\text { dades desenvolvidas pela contabi- } \\
\text { lidade financeira. }\end{array}$ \\
\hline $\begin{array}{l}\text { b) apoiar a avaliação de desempe- } \\
\text { nho, análise de desempenho das } \\
\text { áreas, dos gestores e da entidade; }\end{array}$ & $\begin{array}{l}\text { b) função de avaliação do desempe- } \\
\text { nho e do resultado: acompanhar e } \\
\text { avaliar o desempenho e o resultado } \\
\text { da organização, em todos os níveis; }\end{array}$ & $\begin{array}{l}\text { b) função gerencial estratégica: ati- } \\
\text { vidades que visam o apoio a to- } \\
\text { mada de decisão e ao alcance dos } \\
\text { objetivos organizacionais; }\end{array}$ \\
\hline $\begin{array}{l}\text { c) apoiar a avaliação de resultado, } \\
\text { análise e avaliação do resultado da } \\
\text { instituição, em todas as suas di- } \\
\text { mensões, colaborando par ao de- } \\
\text { senvolvimento dos padrões; }\end{array}$ & $\begin{array}{l}\text { c) função de planejamento: formula- } \\
\text { ção de objetivos, a definição de cená- } \\
\text { rios e a coordenação das atividades } \\
\text { que compõe o planejamento da orga- } \\
\text { nização; }\end{array}$ & $\begin{array}{l}\text { c) função de custos: atividades de- } \\
\text { senvolvidas pela contabilidade de } \\
\text { custos; }\end{array}$ \\
\hline $\begin{array}{l}\text { d) Gerir os sistemas de informa- } \\
\text { ções, elaboração de modelos de de- } \\
\text { cisões e de modelos de informa- } \\
\text { ções para o apoio a gestão }\end{array}$ & $\begin{array}{l}\text { d) função de apoio às operações, de- } \\
\text { senvolvimento de sistemas de infor- } \\
\text { mações que auxiliem na organização } \\
\text { das operações, assim como, na iden- } \\
\text { tificação antecipada dos resultados } \\
\text { destas; }\end{array}$ & $\begin{array}{l}\text { d) função tributaria: atividades de- } \\
\text { senvolvidas pela contabilidade fis- } \\
\text { cal; }\end{array}$ \\
\hline \multirow[t]{4}{*}{$\begin{array}{l}\text { e) atender aos agentes do mercado, } \\
\text { atender as demandas externas a or- } \\
\text { ganização. }\end{array}$} & & $\begin{array}{l}\text { e) função de proteção e controle } \\
\text { dos ativos: atividades de salva- } \\
\text { guarda dos ativos da organização; }\end{array}$ \\
\hline & & $\begin{array}{l}\text { f) função de controle interno: de- } \\
\text { senvolvimento e implantação e o } \\
\text { acompanhamento do sistema de } \\
\text { controle interno; }\end{array}$ \\
\hline & & $\begin{array}{l}\text { g) função de controle de riscos: ati- } \\
\text { vidades de gestão de riscos com a } \\
\text { evidenciação de seus efeitos; }\end{array}$ \\
\hline & & $\begin{array}{l}\text { h) função de gestão de informação: } \\
\text { estas atividades envolvem uma } \\
\text { criação e a modelagem dos siste- } \\
\text { mas de informação de natureza } \\
\text { contábil, financeira, econômica, } \\
\text { patrimonial e gerencial. }\end{array}$ \\
\hline
\end{tabular}

Fonte: Suzart, Marcelino e Rocha (2011).

Borinelli (2006) esclarece que a função de custos é uma função da Controladoria, no entanto, a Federação Internacional de Contadores (IFAC) afirma que há uma maior necessidade de estudos aplicados em custos no setor público (IFAC, 2000).

Nesse sentido, Suzart, Marcelino e Rocha (2011) objetivaram investigar se as funções desempenhadas pelas instituições brasileiras de Controladoria pública diferem das funções definidas pela literatura. Eles analisaram quatorze instituições brasileiras do setor público federal e estadual. Concluíram que as funções desempenhadas pelas instituições brasileiras de Controladoria pública não diferem das funções da Controladoria descritas na literatura especializada. O construto elaborado pelos autores, ou seja, as atividades da Controladoria pública, agrupadas por funções estão apresentadas no Quadro 2. 


\begin{tabular}{|c|c|}
\hline FUNCÃO & \\
\hline Contábil & $\begin{array}{l}\text { - Acompanhar/fiscalizar a gestão contábil, financeira e orçamentária. } \\
\text { - Elaborar demonstrações contábeis. } \\
\text { - Elaborar e manter atualizado o plano de contas do ente federado. } \\
\text { - Gerenciar a contabilidade do ente federado. }\end{array}$ \\
\hline Gerencial-estratégica & $\begin{array}{l}\text { - Acompanhar/fiscalizar a gestão administrativa/operacional. } \\
\text { - Avaliar resultados de planos, de orçamentos e de programas públicos. } \\
\text { - Propor medidas para racionalizar o uso dos recursos públicos. }\end{array}$ \\
\hline Tributária & - Supervisionar a arrecadação e a despesa do ente federado. \\
\hline Proteção e controle dos ativos & - Acompanhar/fiscalizar a gestão patrimonial. \\
\hline Controle interno & $\begin{array}{l}\text { - Apoiar os órgãos de controle externo. } \\
\text { - Planejar, coordenar e executar funções de controle interno. } \\
\text { - Planejar, coordenar e executar funções de corregedoria. } \\
\text { - Planejar, coordenar e executar funções de ouvidoria. } \\
\text { - Zelar pela observância dos princípios de administração pública. }\end{array}$ \\
\hline Controle de riscos & $\begin{array}{l}\text { - Avaliar a execução dos contratos de gestão. } \\
\text { - Prevenir e combater a corrupção. }\end{array}$ \\
\hline
\end{tabular}

Fonte: Suzart, Marcelino e Rocha (2011, p. 53).

Na pesquisa empírica de Wright, Callado e Melo (2013) foi concluído que, diante da percepção dos servidores e da atuação da CGU, que entre as principais atividades de uma Controladoria do setor público devem ser consideradas a coordenação de um sistema de controle interno, a promoção da transparência pública, o estímulo ao controle social e o desenvolvimento de políticas e procedimentos de controle.

Já Scarpin e Slomski (2007) concluíram que a Controladoria governamental, valendo-se de modelos matemáticos de previsão do IDH municipal, pode oferecer subsídios para que a administração pública atinja o ponto ótimo de desenvolvimento humano para determinado município. É importante ressaltar que a Controladoria deve ser um órgão independente, na visão de Silva (2002), para maior veracidade e fidedignidade, entre outras características.

\section{MÉTODO}

\subsection{Caracterização Metodológica}

Ao caracterizar o estudo com base na estrutura proposta por Gil (2008), teve a seguinte configuração: (1) quanto à natureza, é uma pesquisa aplicada; (2) quanto aos objetivos, descritiva, e (3) quanto aos procedimentos, documental. Raupp e Beuren (2006, p. 90), dizem que: “[...] pesquisa documental em estudos que envolvam temas contábeis, no sentido de verificar fatos que possam ser úteis, não apenas como um registro de memória, mas também para ajudar no presente e vislumbrar tendências futuras".

\subsection{Procedimentos}

A pesquisa documental foi realizada mediante a coleta de documentos legais. O estado de Rondônia possui 52 municípios. Foram realizados os seguintes procedimentos: a) análise dos documentos legais que estabelecem as características das instituições públicas estudadas; b) análise dos documentos acessórios que complementam as informações sobre as instituições de Controladoria; c) organização e tabulação dos dados apurados; d) revisão da literatura sobre Controladoria, em especial sobre as funções que são relacionadas a esta; e e) comparação entre as informações obtidas nas análises sobre as instituições de Controladoria pública e as obtidas na literatura. Utilizou-se ainda de entrevistas informais com intuito básico de coletar dados (Gil, 2011) e foram entrevistados três servidores da Controladoria Geral do Município de Vilhena. 
A pesquisa bibliográfica foi desenvolvida através de consulta à literatura sobre a temática da Controladoria, visando identificar seus aspectos chaves e funções típicas. A pesquisa documental foi realizada por meio de coleta dos documentos legais que tratam da criação, da estrutura, da hierarquia e das atribuições das Controladorias das instituições estudadas, assim como da obtenção de informações complementares nos sítios destas instituições, no ambiente da internet. Foi usado um checklist construído por Suzart, Marcelino e Rocha (2011), com base no Quadro 2. Por fim, elaborouse um ranking entre os municípios para identificar o que mais se adequa à literatura e o que menos se adequa com atribuição de 1 ponto ao município para cada função desempenhada de acordo com a literatura.

\subsection{Amostra}

Inicialmente, a proposta seria com a amostra dos dez maiores municípios. No entanto, pelas limitações encontradas na coleta de dados, a mesma compreendeu quatro dos maiores municípios de Rondônia, sendo: Porto Velho, Ji-Paraná, Ariquemes e Vilhena, dos quais foram analisadas as atribuições de suas Controladorias municipais. Devido às dificuldades de se coletar os dados, de modo geral, a amostra caracterizou-se por acessibilidade, segundo Vergara (2013). Tentou-se obter os dados pela home page dos municípios, por telefone e por e-mails, no entanto sem sucesso, obtendose apenas dos quatro municípios mencionados.

O estudo restringiu-se, portanto, pela comparação das Leis no 54/1995, no 125/2001, $n^{\circ}$ 1.208/2003, n 993/2003 e n 1.622/2003, que são as leis de criação da Controladoria dos quatro municípios estudados. Os dados coletados para estudo foram analisados e comparados com a literatura, procurando saber a real situação das Controladorias dos municípios. Para análise dos resultados foram comparadas as leis de criação dos quatro municípios pesquisados, como mostra o Quadro 3. Constata-se ver que Porto Velho possui a Controladoria mais antiga.

Quadro 3 - Relação das Controladorias públicas Municipais pesquisadas.

\begin{tabular}{|c|c|c|}
\hline \multirow{2}{*}{ NOME } & \multicolumn{2}{|c|}{ CRIAÇÃO } \\
\hline & DATA & DOCUMENTO \\
\hline Controladoria Municipal de Porto Velho & 07 de Maio de 2001 & Lei nos $54 / 1995$ e $125 / 2001$ \\
\hline Controladoria Municipal de Ji- Paraná & 30 de Janeiro de 2003 & Lei $n^{\circ} 1208 / 2003$ \\
\hline Controladoria Municipal de Ariquemes & 06 de Maio de 2003 & Lei $n^{\circ} 993 / 2003$ \\
\hline Controladoria Municipal de Vilhena & 29 de Abril de 2003 & Lei $\mathrm{n}^{\circ} 1622 / 2003$ \\
\hline
\end{tabular}

Fonte: Dados da pesquisa (2014).

\section{APRESENTAÇÃO E ANÁLISE DOS RESULTADOS}

No Quadro 4, observa-se as atividades atribuídas às instituições de Controladoria, com base na literatura. As áreas hachuradas correspondem à função não encontrada na lei de criação da Controladoria do respectivo município. Importa destacar que só o município de Porto Velho contempla as atividades "Criar condições para o exercício do controle social" e "Avaliar resultados de planos e de orçamentos públicos". A atividade "Prevenir e combater a corrupção" foi encontrada somente na lei de criação da Controladoria de Ariquemes. Do mesmo modo, a atividade "Supervisionar a arrecadação e a despesa do município" só se encontrou na Controladoria de Ji-Paraná.

Verifica-se também que a função de custos, que Borinelli (2006) define como função da Controladoria, não foi encontrada nas leis municipais pesquisadas. É importante destacar que essas Leis não foram atualizadas até o presente momento. Isso pode ser reflexo da conclusão do que a IFAC afirmou de que há uma maior necessidade de estudos aplicados em custos no setor público (IFAC, 2000). Ressalta-se também que a Secretária do Tesouro Nacional (STN) concedeu um prazo para os municípios se adaptarem e implantarem ou desenvolverem o sistema de custos que termina ainda em 2014 e até o presente momento não foi alterado nas leis municipais pesquisadas. 
Quadro 4 - Atividades atribuídas às instituições de Controladoria pública.

\begin{tabular}{|c|c|c|c|c|}
\hline Funções /Atividades & Porto Velho & Ji-Paraná & Ariquemes & Vilhena \\
\hline 01- Acompanhar/fiscalizar a gestão administrativa / operacional & $X$ & $X$ & $X$ & $X$ \\
\hline 02- Acompanhar/fiscalizar a gestão contábil, financ. orçamentária & $X$ & $x$ & $x$ & $X$ \\
\hline 03- Acompanhar/fiscalizar a gestão patrimonial & $X$ & $X$ & $x$ & $X$ \\
\hline 04- Apoiar os órgãos de controle externo & $X$ & & & $x$ \\
\hline 05- Avaliar a execução dos contratos de gestão & $X$ & & $X$ & \\
\hline 06- Avaliar resultados de planos e de orçamentos públicos & $X$ & & & \\
\hline 07- Criar condições para o exercício do controle social & $x$ & & & \\
\hline 08- Elaborar auditorias & $X$ & $X$ & $x$ & $X$ \\
\hline \multicolumn{5}{|l|}{ 09- Elaborar e manter atualizado o plano de contas do município } \\
\hline \multicolumn{5}{|l|}{ 10-Gerenciar a contabilidade do município } \\
\hline 11- Planejar, coordenar e executar funções de controle interno & $X$ & $X$ & $X$ & $x$ \\
\hline \multicolumn{5}{|l|}{ 12- Planejar, coordenar e executar funções de corregedoria } \\
\hline \multicolumn{5}{|l|}{ 13- Planejar, coordenar e executar funções de ouvidoria } \\
\hline 14- Prevenir e combater a corrupção & & & $X$ & \\
\hline 15- Promover a transparência das ações do setor público & $X$ & $X$ & & \\
\hline \multicolumn{5}{|l|}{ 16- Propor medidas para racionalizar o uso dos recursos públicos } \\
\hline 17- Supervisionar a arrecadação e a despesa do município & & $x$ & & \\
\hline 18- Zelar pela observância dos princípios de administração pública & $X$ & $X$ & $X$ & $X$ \\
\hline Legenda: $X$ - Atividade presente; & \multicolumn{4}{|c|}{ - Atividade ausente. } \\
\hline
\end{tabular}

Fonte: Dados da pesquisa (2014). Observação: Cheklist de Suzart, Marcelino e Rocha (2011), com base no Quadro 2.

Na pesquisa de Suzart, Marcelino e Rocha (2011), a conclusão foi de que as funções desempenhadas pelas instituições brasileiras (14 estados brasileiros) de Controladoria pública não diferem das funções descritas na literatura, mas os autores ressaltaram que as atividades atribuídas às Controladorias públicas ocorrem em pequeno número nas demais funções encontradas, que não a de controle interno. As Controladorias municipais de Rondônia têm suas funções legais de acordo com as descritas na literatura de modo parcial, o que não torna divergente os dois estudos.

Em um dos quatro municípios, após a análise comparativa entre as funções citadas na lei de criação e as da literatura, foi realizada outra visita. Por meio da entrevista informal com quatro servidores da Controladoria Geral do Município (CGM) de Vilhena, entre eles, o controlador geral, procurou-se saber das atividades ausentes, conforme Quadro 4, e dos motivos da ausências dessas funções. No Quadro 5 apresenta-se a percepção deles quanto à realidade atual da presença ou não das atividades conforme a literatura.

Quadro 5 - Atividades ausentes na lei x Práticas atuais.

\begin{tabular}{|c|c|}
\hline Funções /Atividades descritas na literatura, mas não existentes na lei de criação & $\begin{array}{c}\mathrm{N}^{\circ} \text { de respostas confirmatórias } \\
\text { de que é prática atual }\end{array}$ \\
\hline 05- Avaliar a execução dos contratos de gestão & 4 \\
\hline 06- Avaliar resultados de planos e de orçamentos públicos & 4 \\
\hline 07- Criar condições para o exercício do controle social & 3 \\
\hline 09- Elaborar e manter atualizado o plano de contas do município & 2 \\
\hline 10-Gerenciar a contabilidade do município & 1 \\
\hline 12- Planejar, coordenar e executar funções de corregedoria & 1 \\
\hline 13- Planejar, coordenar e executar funções de ouvidoria & 2 \\
\hline 14- Prevenir e combater a corrupção & 4 \\
\hline 15- Promover a transparência das ações do setor público & 4 \\
\hline 16- Propor medidas para racionalizar o uso dos recursos públicos & 4 \\
\hline 17- Supervisionar a arrecadação e a despesa do município & 4 \\
\hline
\end{tabular}

Fonte: Dados da pesquisa (2014). 
Após, procurou-se elaborar um ranking entre os municípios e identificar aquele que mais se adequa e o que menos se adequa à literatura. Com base no Quadro 4, foi atribuído 1 ponto ao município para cada função desempenhada de acordo com a literatura, com possibilidade de um máximo de 18 pontos. Porto Velho obteve 11 pontos, Ariquemes e Ji-Paraná 8, e Vilhena 7 pontos. Pode-se observar também que Porto Velho deixou de pontuar em 7 pontos, Ariquemes e Ji-Paraná em 10, e Vilhena em 11 pontos. A Figura 2 mostra o ranking das Controladorias com maior aderência de suas leis de criação da Controladoria às funções descritas na literatura.

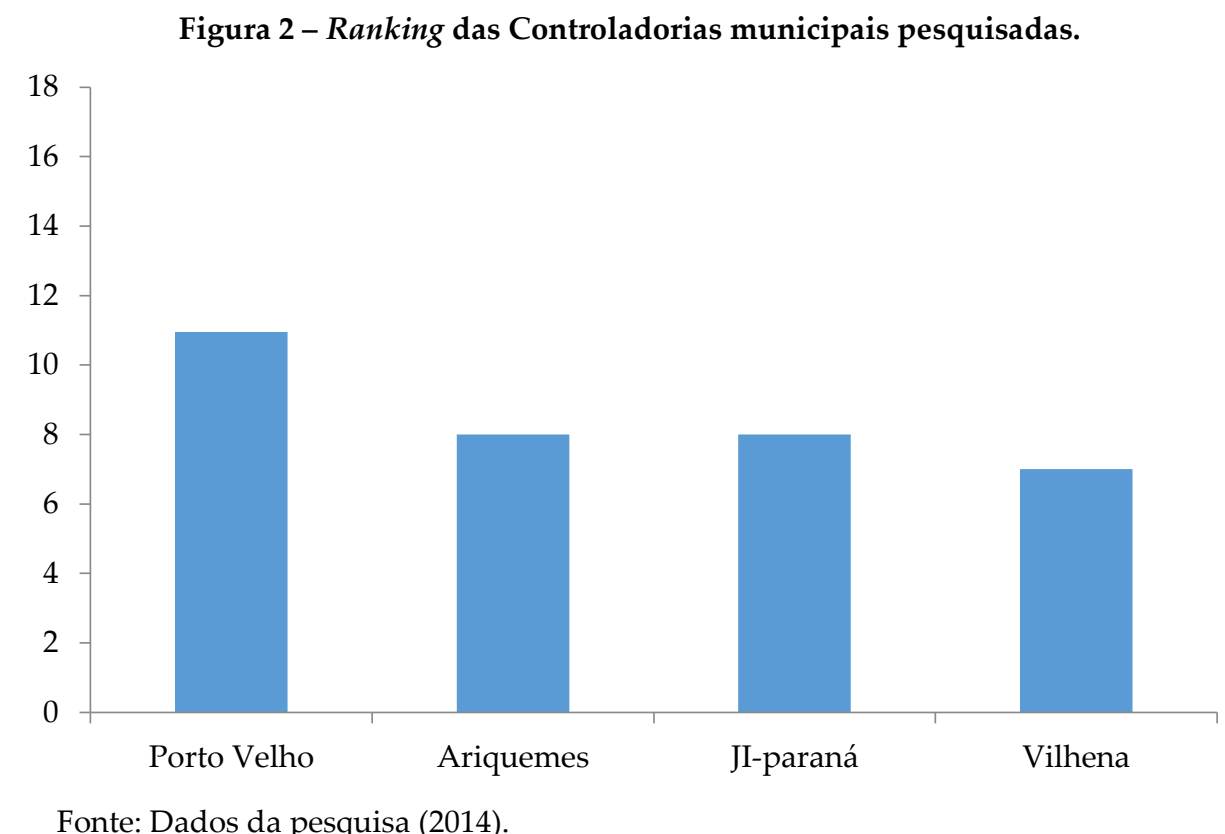

Fonte: Dados da pesquisa (2014).

Porto velho é o município que mais se adequa a literatura da Controladoria seguido pelo municipio Ji-paraná e Ariquemes que ficaram empatados, e em quarto lugar, Vilhena. Sobre a segregação da contabilidade da função financeira (fazendária), como explica Silva (2002), constatou-se que Porto Velho se enquadra no que observou esse autor, pois a contabilidade fica na Controladoria Geral do Município. Ao contrário de Vilhena, onde a contabilidade fica na Secretaria Municipal de Fazenda. Todas as instituições pesquisadas a Controladoria está subordinada ao chefe do poder executivo (prefeito). Mas, há ainda município de grande porte que não implantou a Controladoria Geral do Município, o que denota atraso no desenvolvimento do controle das contas públicas, principalmente, na exigência da implantação e desenvolvimento de sistemas de custos públicos.

\section{CONSIDERAÇÕES FINAIS}

Este artigo procurou responder se as Controladorias municipais tem suas funções de acordo com as descritas na literatura, e o resultado da pesquisa mostrou que algumas funções estão de acordo com as definidas na literatura, outras não, portanto, parcialmente. As funções ou atividades descritas na literatura e não encontradas na Controladoria dos municípios pesquisados foram: elaborar e manter atualizado o plano de contas do município; gerenciar a contabilidade do município; planejar, coordenar e executar funções de corregedoria; planejar, coordenar e executar funções de ouvidoria; e propor medidas para racionalizar o uso dos recursos públicos.

A literatura também descreve que a contabilidade deve ser segregada da função financeira ou fazendária mas, no entanto, constatou-se que na prática dos municípios rondonienses ocorre que o inverso, com exceção da capital. Constatou-se, ainda, que um dos grandes municípios ainda não criou seu órgão de Controladoria, ou está na fase de planejamento e a devida criação. 
Objetivou-se inicialmente uma pesquisa com os dez maiores municipios de Rondônia, porém não foi possível. Tentou-se contato por e-mail, mas sem resposta. Dos municípios pesquisados, apenas o municipio de Porto Velho possui uma home page própria da Controladoria onde foi encontrado sua Lei de criação. A de Ji-Paraná foi obtida por e-mail e em Vilhena foi coletada pessoalmente, com visitas in loco. A Lei de criação da Controladoria de Cacoal não foi encontrada na home page do município e nem em outra página.

Diante disso, como limitação da pesquisa, considerou-se o difícil acesso às informações e obtenção dos dados, o que deixou a amostra reduzida devido a falta de recursos financeiros para viagens e estadias em todos os municípios. No entanto, como as normas da Lei de Responsabilidade Fiscal, da Lei nº 131/2009, conhecida como Lei da Transparência, e da Lei no 12.527/2011, conhecida como Lei de Acesso à Informação, exigem maior transparência (accountability) e publicação nas home pages, percebe-se o não cumprimento, à exceção da capital. Isso denota falta de transparência para a devida instrumentalização do controle social pelo cidadão, descumprindo a atual NBC T 16.1.

Ressalta-se que a literatura sobre Controladoria pública é recente, pois pesquisas concluíram que não há muitas publicações e ainda não há uma elite de pesquisadores sobre a temática. Considerando que sua obrigatoriedade nos municípios é recente e a própria CGU foi criada em 2003, resulta um amplo espaço para debates sobre o tema.

Por fim, sugere-se ampliar a amostra e refazer a análise incluindo os demais municípios do estado, bem como de outros estados. Outra sugestão para nova pesquisa é estudar a percepção ou opiniões dos servidores das Controladorias públicas quanto às funções entre as Leis de criação e a literatura, por meio de pesquisa-ação, pesquisa participante, grupo focal ou do estudo de caso, para verificar os motivos das ausências de algumas funções entre outros objetivos. Como recomendação de ordem prática, salientamos que os municípios rondonienses façam adequação de suas leis e incluam a função de custos, considerando que a literatura afirma ser da Controladoria.

\section{REFERÊNCIAS}

ALMEIDA, L. B.; PARISI, C.; PEREIRA, C. A. Controladoria. In: CATELLI, A. (coord.). Controladoria: uma abordagem da gestão econômica - GECON. 2. ed. São Paulo: Atlas, 2001.

BEUREN I. M.; SCHLINWEIN, A. C.; PASQUAL, D. L. Abordagem da Controladoria em trabalhos publicados no EnANPAD e no Congresso USP de Controladoria e Contabilidade de 2001 a 2006. Revista Contabilidade E Finanças, São Paulo, v.18, n. 45, p. 22-37, 2007.

BORINELLI, M. L. Estrutura conceitual básica de Controladoria: sistematização à luz da teoria e da práxis. Tese (Doutorado em Ciências Contábeis) - Faculdade de Economia, Administração e Contabilidade, Universidade de São Paulo, São Paulo - SP, 2006.

BRASIL. Constituição da República Federativa do Brasil. Brasília, DF: Senado, 1988.

. Lei n⿳‥ 4.320, de 17 de março de 1964. Estatui normas de Direito financeiro para elaboração e controle dos orçamentos e balanços da União, dos Estados, dos Municípios e do Distrito Federal. Disponível em: http://www.planalto.gov.br/legislacao. Acesso em: 10 out. 2014.

. Lei de Responsabilidade Fiscal (2000). Lei Complementar no. 101/00. Estabelece normas de finanças públicas voltadas para a responsabilidade na gestão fiscal e dá outras providências. Brasília: Câmara dos Deputados, 2000. 
CASTRO, D. P. de. Auditoria, contabilidade e controle interno no setor público. 5. ed. São Paulo: Atlas, 2013.

CATELLI, A.; SANTOS E. S. Mensurando a criação de valor na gestão pública. Revista de Administração Pública. Rio de Janeiro, v. 38, n. 3, p. 423-49. 2004.

CATELLI, A. Visão da Controladoria aplicada ao setor público: criando valor para a sociedade. In: MACHADO, N. et al. GBRSP - Gestão baseada em resultado no setor público: uma abordagem para implementação em prefeituras, câmaras municipais, autarquias, fundações e unidades organizacionais. São Paulo: Atlas, 2012.

CAVALCANTE, M. C. N.; DE LUCA, M. M. M. Controladoria como instrumento de governança no setor público. Revista de Educação e Pesquisa em Contabilidade, Brasília, v. 7, n. 1, 73-90, jan./mar. 2013.

CONSELHO FEDERAL DE CONTABILIDADE (CFC). Resolução $n^{\circ}$. 1.135/08. Aprova a NBC T 16.8 - Controle Interno. 2008. Disponível em: http://www.cfc.org.br/sisweb/sre/Default.aspx. Acesso em: 10 out. 2014.

DURIGON, A. R.; DIEHL, C. A. Controladoria no setor público: uma análise dos artigos publicados no Congresso USP de Controladoria e Contabilidade - período de 2001 a 2011. Contabilidade Vista \& Revista, Belo Horizonte, v. 24, n. 2, 91-109. 2013.

GIL, A. C. Como elaborar projetos de pesquisa. 4. ed. São Paulo: Atlas, 2008. Métodos e técnicas de pesquisa social. 6.ed. São Paulo: Atlas, 2011.

IFAC - INTERNATIONAL FEDERATION OF ACCOUNTANTS. Perspectives on Cost Accounting for Government. New York: IFAC. 2000. (Public Sector Committee - Study 12). Disponível em: http://www.ifac.org/sites/default/files/publications/files/study-12-perspectives-on.pdf. Acesso em: 22 out. 2014.

KALIFE, M. A. Administração pública: Lei de Responsabilidade Fiscal e Controladoria. Revista Eletrônica de Contabilidade da UFSM, v. 1, n. 1, set./nov. 2004.

LUNKES, R. J. et al. Análise da legitimidade sociopolítica e cognitiva da Controladoria no Brasil. Revista Contabilidade E Finanças, São Paulo, v. 23, n. 59, p. 89-101, 2012.

MOSIMANN, C. P.; FISCH, S. Controladoria: seu papel na administração de empresas. 2. ed. São Paulo: Atlas, 1999.

MOURA, V. M.; BEUREN I. M. O suporte informacional da Controladoria para o processo decisório da distribuição física de produto. Revista Contabilidade E Finanças. USP. São Paulo, v. 14, n. 31, p. 45-65, 2003.

OLIVEIRA, A. B. S. Controladoria governamental: governança e controle econômico na implementação de políticas públicas. São Paulo: Atlas, 2010. 
OLIVEIRA, L. M.; PEREZ JUNIOR, J. H.; SILVA, C. A. dos S. Controladoria estratégica. 10. ed. São Paulo: Atlas, 2014.

PELEIAS, I. R. et al. Dez anos de pesquisa científica em Controladoria no Brasil (1997 a 2006). Revista de Administração e Inovação, São Paulo, v. 7, n. 1, p. 193-217, 2010.

PEREZ JUNIOR, J. H.; PESTANA, A. O.; FRANCO, S. P. C. Controladoria de gestão: teoria e prática. São Paulo: Atlas, 1997.

PIAI, M. A. B. Metodologia para implementação de sistema de Controladoria. Dissertação (Mestrado em Engenharia de Produção) - Universidade Federal de Santa Catarina, Florianópolis, SC, 2000.

RAUPP, F. M.; BEUREN, I. M. Metodologia da pesquisa aplicável às ciências sociais. In: BEUREN, I. M. (Org.). Como elaborar trabalhos monográficos em contabilidade: teoria e prática. 3. ed. São Paulo: Atlas, 2006.

SCARPIN, J. E.; SLOMSKI, V. Estudo dos fatores condicionantes do índice de desenvolvimento humano nos município do estado do Paraná: instrumento de Controladoria para a tomada de decisões na gestão governamental. Revista de Administração Pública, Rio de Janeiro, v. 41, n. 5, p. 909-33, 2007.

SCHMIDT, P.; SANTOS, J. L.; MARTINS, M. A. S. Manual de Controladoria. São Paulo: Atlas, 2014.

SILVA, L. M. Contabilidade governamental: um enfoque administrativo. 5. ed. São Paulo: Atlas, 2002. . Contabilidade governamental: um enfoque administrativo. 7. ed. São Paulo: Atlas, 2004. . Contabilidade governamental: um enfoque administrativo da nova contabilidade pública. 9. ed. São Paulo: Atlas, 2011.

SILVA, E. F. Controladoria na administração pública. São Paulo: Atlas, 2013.

SOUZA, M. A.; ORTIZ, A. C. S.; ALMEIDA, L. B. Sistemas de informações gerenciais de Controladoria em órgãos públicos: um estudo nos municípios matogrossences da região sudoeste. In: XXXVII Encontrado da Associação Nacional de Pós-Graduação e Pesquisa em Administração. Anais... ANPAD. Rio de janeiro/RJ, 2013.

SLOMSKI, V. Controladoria e governança na gestão pública. São Paulo: Atlas, 2007.

SUZART, J. A. S.; MARCELINO, C. V.; ROCHA, J. S. As instituições brasileiras de Controladoria pública - teoria versus prática. Contabilidade, Gestão e Governança, Brasília, v. 14, n. 1, p. 44-56, 2011.

VERGARA, S. C. Projetos e relatórios de pesquisa em administração. 14. ed. São Paulo: Atlas, 2013.

WRIGHT, G. A.; CALLADO, A. L. C.; MELO, M. M. D. As funções da Controladoria no setor público: a percepção de quem faz a Controladoria Geral da União. In: $13^{\circ}$ Congresso USP de Controladoria e Contabilidade. Anais... USP. São Paulo/SP, 2013. 